\title{
MODELING LEAD Time DEMAND IN CONTINUOUS REVIEW INVENTORY SYSTEMS
}

\author{
Edin Kadric*, Hadis Bajric \& Mugdim Pasic
}
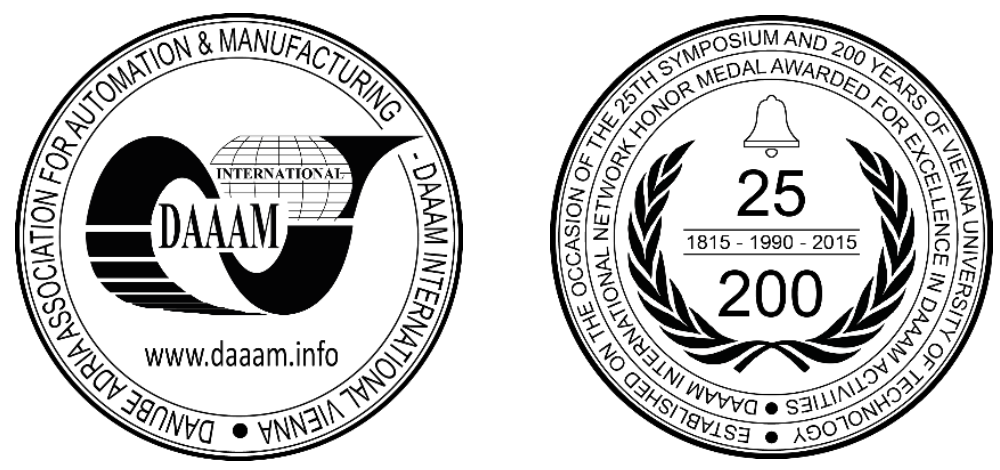

This Publication has to be referred as: Kadric, E[din]; Bajric, H[adis] \& Pasic, M[ugdim] (2017). Modeling Lead Time Demand in Continuous Review Inventory Systems, Proceedings of the 28th DAAAM International Symposium, pp.01800186, B. Katalinic (Ed.), Published by DAAAM International, ISBN 978-3-902734-11-2, ISSN 1726-9679, Vienna, Austria

DOI: $10.2507 / 28$ th.daaam.proceedings.024

\begin{abstract}
Inventory systems that use continuous review policy are under risk during lead time, when stock-out can occur. Therefore, system must have enough on-hand units to prevent such situations. Generally, in inventory control literature it can be found that lead time demand follows normal distribution and all other conclusions are derived from this assumption. However, in real life this does not have to be true, so it is of crucial importance to get better estimates of stochastic demand parameters over lead time. The objective of this research is to estimate the optimal $(s, Q)$ continuous review inventory policy parameters that reduce risk of stock-out during lead time and to enhance robustness of such estimated parameters. This is done using approach we propose for demand modeling. Performances and adequacy of the proposed approach for lead time demand modeling, with various demand patterns, and its application in $(s, Q)$ continuous inventory models are obtained by simulation and show very good results.
\end{abstract}

Keywords: lead time; stochastic demand; continuous review inventory control; grouped demand; overlapping periods

\section{Introduction}

In many situations the assumption of known, deterministic demand and lead time is not necessarily realistic. The demand for each time period is not known in advance. The lead time of items can be uncertain for several reasons such as machine breakdowns, quality or transportation issues. In [1] it is shown that studying the behaviour of the demand and the lead time are essential in order to achieve a useful representation of the system to take proper decisions. Significant research is developed on optimal inventory policies by assuming that demands are independent and follow certain distributions [2]. In practice it is common to assume that the lead time demand follows a particular distributional family [3]. A simplistic approach to modelling uncertainty in the continuous review system is to assume that lead time demand is normally distributed.

Use of the normal distribution or another standard probability density function for lead time demand, or a deterministic lead time assumption, can permit an analytical solution for inventory control parameters, and such results have revealed significant insights into the nature of optimal policies in inventory systems modelled under a variety of conditions [4]. Analytical evaluation in [3] has revealed that the lead time demand should not be approximated by the Poisson distribution unless the variance-to-mean ratio is exactly 1 , and that the gamma and the negative binomial distributions yield fairly 
good results especially when there is much more variability in data. So in order to avoid stock-out and to achieve higher target or service level it is necessary to decrease the uncertainty of the demand fluctuation with a more accurate forecasts or by increase of the safety stocks to cover the fluctuating demands [5]. Increasing safety stocks results in higher average inventory levels and higher holding costs, but at the same time it decreases risk of stock-out and penalty costs. Ratio of penalty cost to holding cost may range from 100 to 400, depending on nature and purpose of item [6]. According to findings in [7], traditional approaches in estimation of lead time demand variance, essential for safety stock calculations, can lead to safety stocks that are up to $30 \%$ too low and service levels that are up to $10 \%$ below the target. In continuous review, system is under risk during lead time, and to reduce risk and avoid stock-out it is very important to accurately predict lead time demand and estimate its parameters.

Estimating demand parameters, such as expected value and variance, for periods longer than time unit, e.g. lead time, can be achieved by multiplying expected daily demand by length of period and by variance. Problems arise when demand data are available for short time horizons. In this paper we are presenting new approach for demand modelling which increases number of demand data sufficient for reliable estimation of lead time demand parameters. First, we consider all demand data available in given time horizon, instead of just lead time demand data. This way it is obvious that more demand data is available, but it is also justified because replenishment process in continuous review models, is stochastic in nature. In traditional approach, demand parameters are estimated by considering only demand over lead time. Lead time length can be constant, but start of replenishment process is not known in advance, hence using only demand over lead time can lead to very poor estimates. Secondly, all available demand data, in given time horizon, are grouped into periods of desired length that mutually overlaps, yielding the same number of demand data. Newly generated demand data represent demand per period and contain all possible realizations of demand per period, while in traditional models demand data are given per day.

Proposed approach to lead time demand modelling is tested on fast and slow moving items using $(s, Q)$ continuous review inventory model. Continuous review model used in analysis differs from traditional ones in terms that define demand parameters, such as average lead time demand and probability density function of lead time demand. As demand parameters obtained using our approach are more reliable and robust than those obtained using traditional approach, policy parameters of used continuous review model are also more accurate and robust. Results have shown that $(s, Q)$ continuous review model provides optimal continuous review inventory policy parameters, which reduce risk of stockout during lead time and enhance robustness of model parameters.

\section{Modelling of the lead time demand}

Lead time is defined as the time that elapses from the time order is placed and the time order is received. In continuous review inventory systems order is placed when the inventory level reaches reorder point $s$. During the lead time, system is under risk of stock-out due to stochastic nature of demand. To avoid stock-out and penalty costs, system must have sufficient on-hand inventories to satisfy demand over lead time. Two most important factors in estimating reorder point are lead time demand and its length. As lead time demand is more volatile and lead time length is longer then reorder point is higher, and vice versa. Expressions for calculation of lead time demand, whether lead time length is deterministic or variable, are shown below.

\section{Case: variable demand and constant lead time}

If average demand is $\bar{x}$ and its variance is $v$, and lead time length is constant $L$, then expected lead time demand $\bar{x}_{L}$ and its variance $v_{L}$ over lead time, can be calculated using following expressions:

$$
\begin{aligned}
& \bar{x}_{L}=\bar{x} \cdot L \\
& v_{L}=v \cdot L
\end{aligned}
$$

\section{Case: variable demand and variable lead time}

If lead time length is variable with expected length $\lambda$ and variance $\omega$, and if expected demand is $\bar{x}$ with variance $\nu$, then expected lead time demand $\bar{x}_{L}$ and its variance $v_{L}$ over lead time, can be calculated using following expressions:

$$
\begin{aligned}
& \bar{x}_{L}=\bar{x} \cdot \tau \\
& v_{L}=\lambda \cdot v^{2}+\bar{x}^{2} \cdot \omega
\end{aligned}
$$

Above expressions are appropriate and valid in situations when demand follows normal distribution. In situations when demand distribution does not follow normal distribution, expressions presented above, generally are not appropriate for estimation of demand parameters for periods longer then unit time. More details and discussions about estimation of demand parameters for time periods longer then time unit can be found in [8]. In order to obtain more robust lead time demand parameters, we present our approach to lead time demand modeling below. 
If historical demand data are available, we divide original time series into periods of equal lengths $L$. Then we sum demand in every period and obtain demand that represent first 'period' time series. In the next step, we create second demand time series, in such way that first demand from original time series is set to the end of the original time series. New time series is then again divided into periods of length $L$, demand is summed, and second 'period' times series is obtained. This procedure is repeated $L-1$ times. Presented approach of grouping demand data by overlapping periods of 7 days length, is graphically presented on Fig. 1.
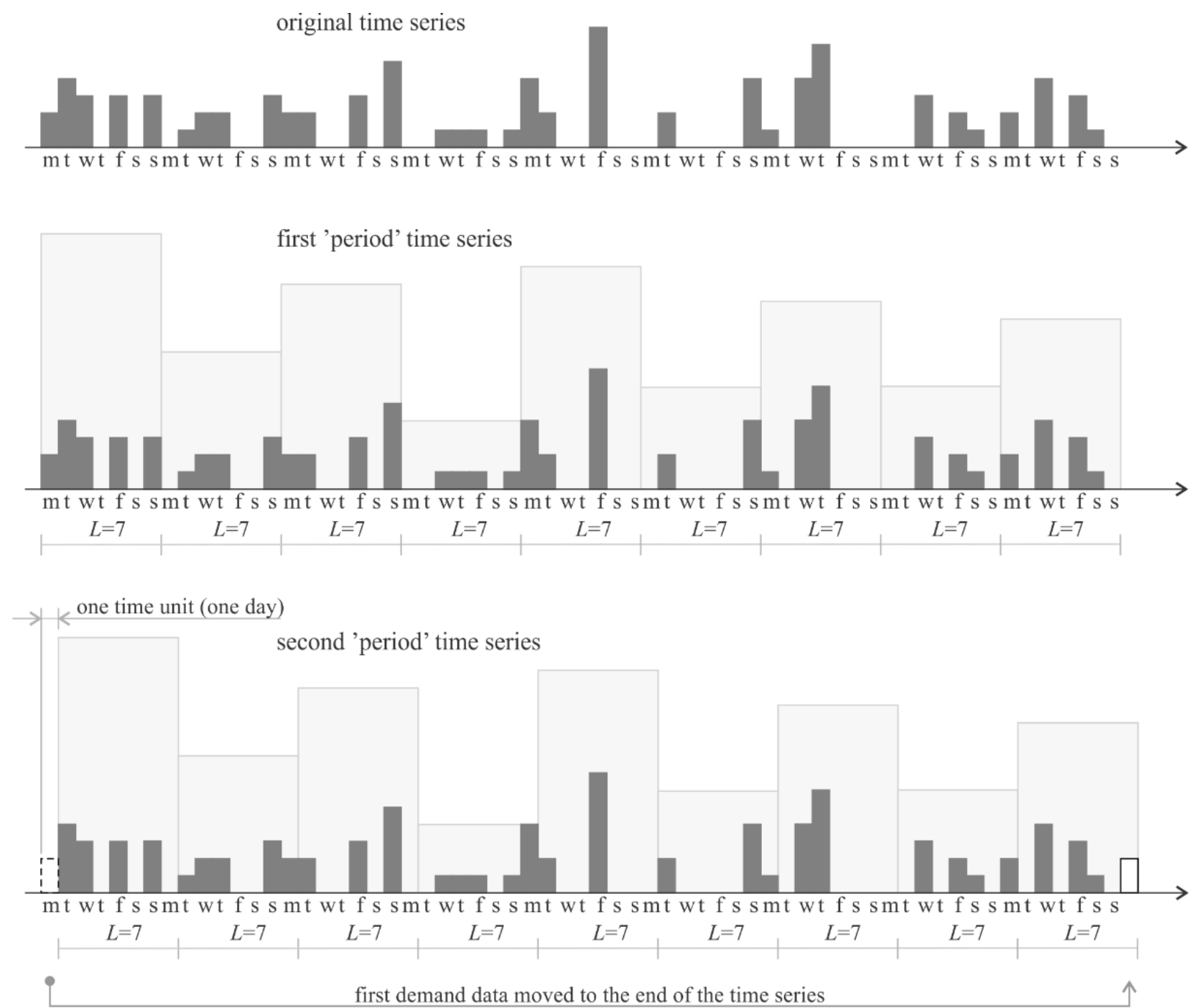

Fig. 1. Graphical presentation of demand modelling with periods that overlaps.

When all 'period' time series are constructed then it is possible to proceed with lead time demand analysis in two directions: first one uses all 'period' time series to estimate demand parameters, while the second one uses just one 'period' time series with lowest variance.

If all 'period' time series are used in analysis then we can expect that expected demand will be close to that estimated using (1), while demand variance will be higher than that estimated using (2). As lead time length is longer then lead time demand variance will be higher. Higher lead time demand variance increases reorder point level $s$, holding and total costs, but at the same time risk of stock-out is lesser and less affected by sudden changes in demand and supplier response and will have lower penalty costs. We propose this approach to be used in uncertain environments, where lead time and lead time demand is volatile and suppliers unreliable.

Second approach considers choosing one, among all, 'period' time series with lowest lead time demand variance. Opposite to above explained approach, this approach will result with lower reorder point level $s$, holding and total costs, but this approach is prone to risk. Sudden changes in demand can lead to significant variance increase, and then to stockout occurrence. Stock-out will decrease service level and increase penalty and total costs. We propose this approach to be used in systems that operate in certain and stable environments. 


\section{Formulation of $(s, Q)$ continuous inventory model}

We consider single item, single location, and continuous review inventory control problem with allowed backorders. We suppose that demand in successive time periods is positive, random, independent and identically distributed variable. When system has positive inventory level, all customer demands are satisfied immediately from inventories on stock. When system is out of stock, we suppose that customers are willing to wait for next order delivery to satisfy their demand, so all unsatisfied demand is backordered. When next order arrives, backorders are satisfied first and then regular demands.

When system has positive inventory levels, then for every item unit on-hand per time unit, holding cost is charged. As exact number of item units on-hand is not known in advance, holding cost is charged on expected number of item units on-hand. For every item unit, system is charged $h_{d}$ currency units per time unit. When system is out-of-stock than for every backordered unit, system is charged $\pi$ currency units per item unit. We suppose that lead-time $L$, the time between placing and receiving an order is constant. There is no order overlapping and in any time period system has the most one outstanding order.

Proposed mathematical model of expected total cost function is defined by two parameters: reorder point $s$ and fixed order quantity $Q$. The expected total $\operatorname{cost} C(s, Q)$ for proposed continuous review inventory model, is given by expression:

$$
C(s, Q)=A \cdot \frac{D_{H}}{Q}+h_{H} \cdot\left[\frac{Q}{2}+\int_{0}^{s}\left(s-x_{L}\right) \cdot f\left(x_{L}\right) d x_{L}\right]+\frac{D_{H}}{Q} \cdot \pi \cdot \int_{s}^{+\infty}\left(x_{L}-s\right) \cdot f\left(x_{L}\right) d x_{L}
$$

Where: $A$ = fixed ordering cost, $D_{H}=$ total demand over considered time horizon, $h_{H}=$ holding cost per item unit over considered time horizon, $x_{L}=$ expected demand over lead-time, $f()=$. probability density function of demand over leadtime.

Deriving expected total cost function $C(s, Q)$, given by (5), over parameters $s$ and $Q$, and equaling derivatives to zero, gives optimal values of control parameters $S$ and $Q$.

$$
\begin{aligned}
& \frac{\partial C(s, Q)}{\partial Q}=-\frac{A \cdot D_{H}}{Q^{2}}+\frac{h_{H}}{2}-\frac{D_{H} \cdot \pi}{Q^{2}} \cdot N_{L}=0 \\
& \frac{\partial C(s, Q)}{\partial s}=h_{H} \cdot \int_{0}^{s} f\left(x_{L}\right) d x_{L}-\frac{D_{H}}{Q} \cdot \pi \cdot \int_{s}^{+\infty} f\left(x_{L}\right) d x_{L}=0
\end{aligned}
$$

From (2) follows:

$$
\begin{aligned}
& -\frac{A \cdot D_{H}}{Q^{2}}+\frac{h_{H}}{2}-\frac{D_{H} \cdot \pi}{Q^{2}} \cdot N_{L}=0 \\
& -A \cdot D_{H}+\frac{h_{H} \cdot Q^{2}}{2}-D_{H} \cdot \pi \cdot N_{L}=0 \\
& Q=\sqrt{\frac{2 \cdot D_{H} \cdot\left[A+\pi \cdot N_{L}\right]}{h_{H}}}
\end{aligned}
$$

From (3) follows:

$$
\begin{aligned}
& h_{H} \cdot F_{L}(s)-\frac{D_{H}}{Q} \cdot \pi\left[1-F_{L}(s)\right]=0 \\
& F_{L}(s)\left[h_{H}+\frac{D_{H}}{Q} \cdot \pi\right]-\frac{D_{H}}{Q} \cdot \pi=0 \\
& F_{L}(s)=\frac{D_{H} \cdot \pi}{D_{H} \cdot \pi+h_{H} \cdot Q}
\end{aligned}
$$

Where: $N_{L}=$ expected number of backorders, $F_{L}()=$. cumulative probability density function of demand over lead-time.

Using known inverse cumulative distribution function of demand over lead-time given by (9), or numerical methods, it is possible to find optimal value of reorder point $s$, which minimizes total cost function.

Considering expression (8) for optimal fixed order quantity $Q$, it can be seen that it is very similar to well known $E O Q$ quantity. Only difference is that, in particular circumstances, fixed ordering cost $A$ is replaced with $A+\pi \cdot N_{L}$ cost. Economical meaning of this difference is that ordering cycle implies not only the fixed ordering cost but also the risk of stock-out, before supplier delivers ordered units. Because of the risk of stock-out companies try to increase ordering 
quantity $Q$ in order to avoid frequent orderings. Every time order is placed there is the risk that demand over lead-time will be larger than reorder point $s$, which leads to inventory stock-out and customer dissatisfaction. Generally, continuous inventory control models with allowed backorders will have larger ordering quantity $Q$ then basic EOQ model. This increase in ordering quantity will be larger if penalty cost $\pi$ is larger and reorder point $s$ is smaller, because probability of stock-out will increase.

Using expressions (8) and (9) to find optimal values of $s$ and $Q$ is not simple because each variable is dependent on each other. Since optimal values of $s$ and $Q$ can not be estimated directly by analytical methods, it is possible to use iterative procedure. The essence of the iterative procedure can be roughly explained in the following way: initially an approximate real value is chosen for the order quantity, which is $Q$ from the EOQ model. Then using this value for the optimal order quantity, which can be represented by $Q_{0}$, determine the initial estimate for the reorder point $s_{0}$. Using the initial estimate for $s_{0}$, it is possible to find better estimate for the fixed order quantity $Q_{1}$, and so on. The iterative process stops when $Q_{i} \approx Q_{i-1}$ or when $C_{i}(s, Q)-C_{i-1}(s, Q) \leq \varepsilon$, where $\varepsilon=$ cost treshold, and $i=$ iteration number.

\section{Verification and testing of proposed approach to lead time demand modelling}

To verify and test proposed approach to lead time demand modelling and its performance in continuous review inventory model it is necessary to compare values of model performance indicators to those of simulation. Values of simulation performance indicators are considered exact ones. Simulation is performed using proposed continuous review inventory model and its input and control parameters on real demand data. Performance indicators used in this experimental setting are: $P_{1}$ and $P_{2}$ service levels, average inventory level, expected value of backordered units, total and component costs.

Verification and testing are conducted on real life examples. Items used in analysis significantly differ in parameters such as: purchase and selling price, demand frequency, value and variance. Selected items have relatively low and high values of these parameters. Item 1 is from grocery group and is widely available in the most grocery stores. Data for Item 1 , used in analysis, are as follows: time horizon length is 355 days, total demand in time horizon is 16424 units, daily demand is 46.20, standard deviation is 29.87 , purchase price $c=1.64 € /$ unit, fixed ordering cost $A=10 € /$ order, backorder cost $\pi=$ $0.70 € /$ unit backordered, holding cost $h_{d}=0.001348 € /$ unit/day. Frequency, demand value and variance for Item 1 are high, so it can be classified as fast moving item. Item 2 is household air-conditioning device and is available in the most home appliances stores. Data for Item 2, used in analysis, are as follows: time horizon length is 247 days, total demand in time horizon is 18 units, daily demand is 0.07 , standard deviation is 0.25 , purchase price $c=376.72 € /$ unit, fixed ordering cost $A=50 € /$ order, backorder cost $\pi=100 € /$ unit backordered, holding cost $h_{d}=0.31 € /$ unit/day. Frequency, demand value and variance for Item 2 are low, so it can be classified as slow moving item.

To estimate accuracy and reliability of proposed inventory model two measures have been used: error or deviation of model performance indicators to those simulated, and relative error used to estimate relative deviations of performance indicators. Error $\Delta_{j}$ is difference between values of $j$-th model and simulation performance indicator and can be calculated using following expression:

$$
\Delta_{j}=\text { Model }_{j}-\text { Simulation }_{j}
$$

where: Model $_{j}-$ value of $j$-th model performance indicator, Simulation ${ }_{j}-$ value of $j$-th simulation performance indicator. If error $\Delta_{j}$ is negative, than it means that model underestimates $j$-th performance indicator value, meaning real value is greater, and if error $\Delta_{j}$ is positive, than it means that model overestimates $j$-th performance indicator value, hence real value is smaller. Error shows how much expected value differs from exact one, but it does not show degree of sensitivity. To estimate sensitivity of differences we have used relative error. Relative error $\Delta_{j} \%$ of $j$-th performance indicator, can be calculated using following expression:

$$
\Delta_{j} \%=\frac{\Delta_{j}}{\text { Simulation }_{j}} \cdot 100 \%
$$

Error and relative error of total cost, as one of the performance indicators, are especially important, because control parameters of proposed inventory model are obtained using this indicator. Errors and relative errors of other performance indicators are also important in analysis of trade-offs between average inventory levels and backorders, i.e. holding and backorder costs, and can be used to further improve inventory control model.

Optimal values of maximum reorder point $s$ and fixed order quantity $Q$, as well as values of performance indicators with their relative errors are shown in tables below. Relative errors of performance indicators for which simulation value is equal to 0 could not be calculated and are represented with hyphen (-). 


\begin{tabular}{|l|r|r|r|}
\hline Lead time $L$ & 2 & \multicolumn{1}{c|}{5} & \multicolumn{1}{c|}{7} \\
\hline Reorder point $S$ & 179 & 366 & 516 \\
\hline Fixed order quantity $Q$ & 840 & 847 & 831 \\
\hline Performance indicators & \multicolumn{3}{|c|}{ Relative error, \% } \\
\hline$P_{1}$ service level & 0,0000 & 0,0000 & 0,0000 \\
\hline$P_{2}$ service level & $-0,0487$ & $-0,0731$ & $-0,0122$ \\
\hline Average inventory level & 0,1224 & $-0,2401$ & $-0,9518$ \\
\hline Backorders & - & - & - \\
\hline Ordering cost & 0,0000 & 0,0000 & 0,0000 \\
\hline Holding cost & 0,1196 & $-0,2379$ & $-0,9521$ \\
\hline Backorder cost & - & - & - \\
\hline Total cost & 1,3313 & 1,6545 & $-0,2833$ \\
\hline
\end{tabular}

Table 1. Comparative view of optimal control values and values of relative errors of performance indicators of $(s, Q)$ model for Item 1 and lead times lengths of 2, 5 and 7 days.

It can be seen from Table 1 . that for Item 1 classified as fast moving item, model performance indicators match very well simulation ones, with relative errors less than $2 \%$.

\begin{tabular}{|l|r|r|r|}
\hline Lead time $L$ & 2 & \multicolumn{1}{|c|}{5} & \multicolumn{1}{c|}{7} \\
\hline Reorder point $s$ & 0 & 1 & 1 \\
\hline Fixed order quantity $Q$ & \multicolumn{1}{|c|}{5} & \multicolumn{1}{|c|}{5} & \multicolumn{1}{|c|}{5} \\
\hline Performance indicators & 0,0000 & 0,0000 & 0,0000 \\
\hline$P_{1}$ service level & 0,0000 & 0,0000 & 0,0000 \\
\hline$P_{2}$ service level & $-20,6349$ & $-10,8635$ & $-9,0379$ \\
\hline Average inventory level & 0,0000 & 0,0000 & 0,0000 \\
\hline Backorders & 0,0000 & 0,0000 & 0,0000 \\
\hline Ordering cost & $-20,6145$ & $-10,9649$ & $-9,1388$ \\
\hline Holding cost & 0,0000 & 0,0000 & 0,0000 \\
\hline Backorder cost & $-9,2005$ & $-5,2528$ & $-4,2734$ \\
\hline Total cost & \multicolumn{3}{|l}{} \\
\hline
\end{tabular}

Table 2. Comparative view of optimal control values and values of relative errors of performance indicators of $(s, Q)$ model for Item 2 and lead times lengths of 2, 5 and 7 days.

Analysis of Item 2 shows lack of model to more accurately estimate on-hand units, hence relative errors of average inventory level and holding cost are some high. Relative errors of total cost do not exceed $10 \%$, but it can be seen that as lead time length becomes longer, relative errors become smaller. When lead time is 2 days model actually becomes EOQ model.

\section{Conclusion}

In this paper new approach to lead time demand modeling and its application in continuous review inventory model is presented. Proposed approach to lead time demand modelling enables significant improvements of demand parameters estimation with higher reliability and robustness. Generally, advantages of proposed approach to ones typically used in inventory control literature and practice, can be summarized as follows:

- Large enough sample of grouped demand data, used for estimation of reliable and robust lead time demand parameters, even in situations when limited lead time demand data are available.

- Lead time demand data obtained using proposed approach are less sensitive to sudden changes in demand, such as unexpected increase or decrease of demand during some periods.

- Lead time demand data contain all the possible realizations of demand per period that can occur in the considered time horizon.

Relative errors of model performance indicators are acceptable, even the items used in the analysis significantly differ in demand and cost properties. Optimization results are especially good for fast moving item (Item 1), with relative errors less than $2 \%$, for all lead time lengths used in analysis. Optimization results for slow moving item (Item 2) are poorer, with relative errors less than $10 \%$ for lead time length of 2 days, but for longer lead times as 5 and 7 days, relative errors are less than $5 \%$. 
Future research should focus on better estimation of expected number of on-hand units and to them related holding costs, in order to improve overall model, especially in case of slow moving items.

\section{References}

[1] Roldán, R.F., Basagoiti, R. \& Coelho, L.C. (2016). A survey on the inventory-routing problem with stochastic lead times and demands, J. Appl. Log., in press

[2] Hnaien, F.\& Afsar, H.M. (2017). Robust single-item lot-sizing problems with discrete-scenario lead time. International Journal of Production Economics 185 (2017) 223-229, ISSN: 0925-5273

[3] Rossetti, M.D. \& Unlu, Y. (2011). Evaluating the robustness of lead time demand models. Int. J. Production Economics, 134 (2011), pp. 159-176, ISSN: 0925-5273

[4] Cobb, B.R., Johnson, A.W., Rumí, R. \& Salmerón, A. (2015). Accurate Lead Time Demand Modeling and Optimal Inventory Policies in Continuous Review Systems. International Journal of Production Economics 163 (2015), pp. 124-136, ISSN: 0925-5273

[5] Korponai, J.; Banyai, A. \& Illes, B. (2015). The Effect of the Demand-Changes on the Inventories, Proceedings of the 26th DAAAM International Symposium, pp.1068-1075, B. Katalinic (Ed.), Published by DAAAM International, ISBN 978-3-902734-07-5, ISSN 1726-9679, Vienna, Austria DOI: 10.2507/26th.daaam.proceedings.150

[6] Huh, W.T., Janakiraman, G., Muckstadt, J.A. \& Rusmevichientong, P. (2009). Asymptotic Optimality of Order-UpTo Policies in Lost Sales Inventory Systems. Management Science, Vol. 55, No. 3, pp. 404-420, ISSN: 0025-1909

[7] Prak, D., Teunter, R. \& Syntetos, A. (2016). On the calculation of safety stocks when demand is forecasted. European Journal of Operational Research, Vol. 256, Issue 2, pp. 454-461, ISSN: 0377-2217

[8] Kadric, E., Bajric, H. \& Pasic, M. (2015). Demand Modeling with Overlapping Time Periods. Procedia Engineering 100 (2015) 305 - 313, doi: 10.1016/j.proeng.2015.01.372 